\title{
Analysis of the Teaching Reconstructions and Restraining Factors of Flipped Classroom
}

\author{
Ling REN \\ School of Foreign Languages, Anshan Normal University, Anshan, China \\ Email: renling416@163.com
}

\begin{abstract}
As a new pattern of teaching today, flipped classroom is considered as an instructional strategy and a type of blended learning that reverses the traditional learning environment by delivering instructional content, often online, outside of the classroom. In flip teaching, the whole process will experience three different stages, including self-study, classroom teaching and teaching evaluation. Meanwhile, flipped classroom has some distinguishing features such as clear information, reversed process and proper evaluation, etc., which can free class time for hands-on work and benefit both the advanced and less advanced students. Although some restraining factors including teachers, students, schools and parents have deep influence on the teaching effect of flipped classroom, the implementation of flipped classroom in the information age will definitely change the traditional educational system and gradually accepted by people, which is of great value to fostering future diversified and innovative talents.
\end{abstract}

Keywords-Flipped Classroom; Teaching Mode; Reconstructed Process, Restraining Factors

\section{DEFINITION AND IMPLICATIONS OF FLIPPED ClasSROOM}

Flipped classroom is an instructional strategy and a type of blended learning that reverses the traditional learning environment by delivering instructional content, often online, outside of the classroom. It moves activities, including those that may have traditionally been considered homework, into the classroom. In a flipped classroom, students watch online lectures, collaborate in online discussions, or carry out research at home and engage in concepts in the classroom with the guidance of a mentor [1].

Unlike traditional teaching methods, the new type of flipped classroom means that teachers make video recording courses for students to preview before class, and they no longer explain the texts in details but only answer questions and organize discussions. The first attempt of flipped classroom was made by two high school teachers in Colorado for tutoring the students who were absent, and was later promoted. The implementation of flipped classroom is considered a major change in classroom teaching methods. Once upon a time some mainstream media such as The Globe and Mail and The Wall Street Journal have given special coverage of this teaching method, and the relevant education experts have also highly appreciated it.
Most of the traditional teaching methods require students to listen to the teaching contents in the classroom, then review and consolidate the knowledge after class in order to get a deeper understanding and more comprehensive grasp. However, flipped classrooms subvert the traditional teaching pattern in recent years. In the teaching process, teachers firstly make the video recording of teaching materials before class, so that students can use it for pre-class learning. In the class, teachers mainly focus on the guidance, $\mathrm{Q} \& \mathrm{~A}$ and interaction to test students' preview. In this way, students will complete the learning tasks in the class, which were often taken after class in a traditional classroom, and finally fully understand and grasp the learning contents.

\section{TEACHING PROCESS OF FliPPED ClassRoOM}

\section{A. Self-study}

Flipped classroom is based on the direction of learning contents and skills training to determine the self-learning contents of students. Through the pre-class setup of multimedia assisted learning software, teachers should satisfy the needs of different learners. Generally, according to the specific level of students' learning, the software can be set to three different levels for students to independently choose the learning content after class, actually realizing the reversing function. Similarly, through the after-class setup of self-study content, teachers should take full account of the part of the lesson that cannot be completed during class after class, and move this part to selfstudy after class. Through practice, teachers find out the prevalent problems of students, and emphasize them in classroom teaching in order to accomplish the teaching goal at the best state.

In fact, teachers can monitor the independent learning process of flipped classroom step by step. Through selecting high-quality learning software, teachers can better check the situation of students' after-school learning according to the functions such as daily learning statistics, weekly learning statistics, completion of the task and communication with teachers, etc., which cannot be realized with the traditional teaching methods [2]. 


\section{B. Classroom teaching}

In flip teaching, teachers will make a periodic summary of students' learning conditions, and solve the common problems and further consolidate the protection of class identity.

For individual questions, teachers carry out personalized guidance after class. For example, some video information provided in flipped classrooms are difficult to understand, teachers can explain part of the contents in the classroom. Through discussion, students are interested in the video and audio contents in the classroom, so they give the feedbacks hoping to get teachers' explanations and help. In this case, teachers can deal with the matter by providing students with summary, outline, or details as needed.

\section{Teaching evaluation}

After the phases of self-study and classroom teaching, the unit tasks of students are basically completed. However, the whole learning process has not been completed yet and still needs to be consolidated after class to ensure the learning effectiveness.

After-school consolidation learning can be divided into two parts: the after-school learning tasks arranged by teachers and students' own checkup of learning. One of the main aspects of after-school consolidation is unit testing. With multimedia assisted instruction software, teachers can test various skills in learning and give feedback to students, then give the same type of retest to the errors. At the same time, teachers in the network platform can provide students with learning guidance at any time, better playing the leading role of teaching.

In the session of after-class consolidation, teachers can design a reflective part of student learning, so that students can sort out the acquired knowledge, mastering the skills to understand the learning of the next phase to continue their efforts. Finally, through different phases of self-feedback information, students make a personal formative assessment of their learning in the entire semester [3].

\section{DistingUISHING FEATURES OF FLIPPED CLASSROOM}

In the 1950s, many countries in the world began to carry out radio and television education to explore new ways to teach with video materials. However, it did not bring much impact on the traditional teaching mode. In recent years, with the rapid development of information technology in the era of big data, computers and Internet have become indispensable tools in teaching. Because of the distinct features of the times, flipped classroom has drawn more and more attention from people, and it has a tremendous amount of inherent value to cultivate innovative talents in the future.

\section{A. Clear information}

Most of the teaching videos in a flipped classroom only take a few minutes, a longer video is only about ten minutes. Therefore, the video length is under the control of a proper time range which promotes students' concentration. In addition, teachers' images or the classroom environment which may detract students' attention seldom appear in the teaching videos, in line with the characteristics of physical and mental development of students. What's more, teaching videos are corresponding to specific issues in teaching, facilitating students to find, which can also be freely controlled by students to implement some functions as pause, playback, etc. This is very conducive to students' self-learning.

\section{B. Reversed process}

Flipped classroom reverses the traditional teaching process and teaching structure, upside down the process of knowledge transference and knowledge internalization, readjusting the time inside and outside the classroom [4].

In general, the learning process of students is usually composed of two phases: transference and internalization of knowledge. In traditional classrooms, knowledge transference is usually realized through classroom teaching and interaction between students, and knowledge internalization is completed through practice after class by students themselves. Due to the lack of communication and cooperation with teachers and other students, the internalization phase often frustrates the students and leads to their loss of the motivation and achievement of learning. However, the teaching mode of flipped classroom reconstructs the learning process of students.

In flipped classrooms, knowledge transference is completed by the students before the class. Through the teaching videos provided by teachers and online tutorials, students will have a fundamental grasp of the basic learning content. After that, the internalization of knowledge will be completed through interaction in the classroom in which teachers provide targeted and in-depth guidance and effective counseling. In addition, the communication and collaboration among students are more conducive to promoting students' internalization of knowledge.

\section{Proper evaluation}

The traditional teaching evaluation ignores the teaching process, and it is difficult to reflect the individual differences of students. Under the support of information technology, the evaluation of flipped classroom teaching has changed the endof-course evaluation mode with examinations as the core in teaching evaluation, highlighted the subjectivity and initiative of students in teaching evaluation, and formed a personalized, diversified and systematic teaching evaluation, and finally promoted the unity of teaching and learning.

Flipped classroom teaching videos usually raise several small questions at the end which helps students monitor their understandings of the video content in a timely manner and effectively judge their learning situation. If students still have questions, they can watch the video again and think carefully. After a period of study, students can review and consolidate again through instructional videos.

At the same time, teachers can summarize and deal with the students' questions and answers in time through the cloud platform, thus to grasp students' acquisition of knowledge and make comments accordingly. The follow-up technology of teaching evaluation enables students to obtain relevant aspects of empirical information, which is good for teachers to better understand their students [5]. 


\section{RESTRAINING FACTORS OF FLIPPED ClASSROOM}

Although flipped classroom is known as the teaching revolution, it is not a teaching wonder, the effectiveness of flipped classroom teaching still depends on the comprehensive coordination of teachers, students, schools and families.

\section{A. Teachers}

From the perspective of teachers, teachers' teaching philosophy and professional literacy have a direct impact on the implementing effect of flipped classroom. If teachers' teaching philosophy cannot be correctly established, it may turn over the classroom teaching into a mere formality.

In the current information age, students often face the same information resources with teachers, and the consistent balance of knowledge transference and reception is broken. The overturning of teaching mode accelerates the traditional role of teachers in propagating the doctrine, imparting professional knowledge and resolving doubts. Therefore, only when teachers completely change their teaching philosophy and role identities can the pace of teaching reform be promoted. Moreover, the teaching mode of flipped classroom urgently requires teachers to strengthen their professional literacy and comprehensive quality. Flipped classroom will increase the workload of teachers. In addition to the technical issues involved in the production of video, teachers also need careful planning of classroom activities to guide students to achieve efficient learning. Therefore, teachers should take a correct attitude towards the communication and cooperation with students, studying and solving problems together. In addition, guiding students to learn independently will also become the basic quality of teachers. Compared with the traditional teaching mode, the role of teachers turns from initiative to passive, and from leaders to guides, which has higher requirements for professional literacy. However, it is difficult for teachers who are accustomed to traditional education mode as students to complete their own transformation in a short time.

\section{B. Students}

For students, flipped classroom requires them to have a strong sense and ability of self-study. In a flipped classroom, teachers hand over the dominant position in the classroom, and learning becomes the matter of students themselves. However, although students keep initiative in learning, some students are not good at asking questions, and this will directly affect the teaching effectiveness. Thus, the ability of self-control and autonomous learning is the precondition of the smooth implementation of flipped classroom. Students need to master the learning progress in the learning course, objectively evaluate the effectiveness and conscientiously accomplish teachers' assigning tasks.

As a result, learning adaptability becomes the greater challenge for students in flipped classroom teaching. First of all, the process of knowledge learning is transferred out of class, and it depends on students' themselves to solve most of the learning problems. The task of learning activities and the tolerance of setbacks test students' self-control ability and learning desire, so some students with poor mental tolerance will have problems with the new way of learning. Second, the complexity of the learning environment can also make students uncomfortable. The teaching process of flipped classroom include the following steps. Teachers decompose tasks according to the teaching objectives, and then make relevant supporting learning materials available to students for autonomous learning, and finally initiate classroom reporting, discussion, Q\&A, evaluation and conclusion. In brief, flipped classroom requires students to take the initiative to learn knowledge, otherwise it is difficult to acquire knowledge and improve ability. Third, different learning outcomes will have a significant gap. Flipped classroom turns the direct transference of knowledge into guiding students to acquire knowledge themselves, and the focus of the course moves out of the classroom. At the same time, the classroom provides deep space for interaction of thinking and collision, and leads the collision of ideas to a deeper level. Actually, this is a temporary hard-to-adapt learning predicament for some students, and it is also a serious challenge for teaching and school administration.

\section{Schools and parents}

The attitude of schools and parents has a significant impact on the implementation of flipped classroom. On the one hand, the school management methods and teaching conditions greatly influence the effective implementation of the new teaching mode. Most of the teaching contents are based on teaching videos, and the current hardware environment in schools will inevitably have some effects on the teaching reform. At the same time, overturning the traditional classroom in flipped classroom requires the understanding and support of the school management in such aspects as teaching methods, teacher performance appraisal and student achievement evaluation.

On the other hand, parents are very concerned about how to quantify the effectiveness of teaching in flipped classroom. Although parents today have new ideas about their children's education, they still attach importance to examinations and evaluation methods that quantify teaching effectiveness and students' learning. Under the influence of the concept of quality education, parents pay more attention to their children's all-round development. Therefore, flipped classroom which reconstructs the teaching process must have its corresponding end-result evaluation mechanism.

\section{CONCLUSION}

Since the 21 st century, with the rapid development of multimedia and network technologies, digital mobile devices have been continuously introduced. In the traditional pattern of teaching, students are assigned to read textbooks and work on problem setting out of class, and listen to lectures and take test in class. However, flipped classroom requires students to learn knowledge online by watching video lectures, usually out of class, and teachers can offer more personalized guidance and interaction with students. In this way, flipped classroom frees class time for hands-on work, so that students can communicate and cooperate with each other, which is of great value to fostering future diversified and innovative talents.

Flipped classroom emphasizes the combination of pre-class study and classroom teaching, and gives full play to the 
advantages of modern information technology. Therefore, it puts forward higher requirements for teachers. Students come into the classroom with questions, teachers make targeted explanations to students and allowing them to fully interact for independent thinking. Meanwhile, more time and energy are left to students, reflecting their dominant position in the classroom. It is believed each course can use flipped classroom with its own teaching features and methods. In the background of informatization of global education, the development of multimedia classrooms and online learning platforms and the use of various multimedia aids can fully reflect the initiative, enthusiasm and creativity of students. In a word, flipped classroom has gradually become the focus of education circles at home and abroad, which is triggering profound changes in education. The new teaching mode based on flipped classroom has a positive effect on stimulating students' interest, cultivating their learning ability and improving their practical competence.

\section{REFERENCES}

[1] https://en.wikipedia.org/wiki/Flipped_classroom.

[2] D. M. Wen, An Empirical Survey on the Correlation Between Teachers' Roles and Students' Autonomous Learning Ability, J, Journal of Baoding University, 2015(4), pp.111-114.

[3] M. X. Shi, How to Help University Students Improve Learning AfterClass Competence and Effect, J, Education Circle, 2014(3), pp.95-96.

[4] G. F. Zhou, Flipped Classroom: Innovation and Development in the Succession, J, Educators, 2017(15), pp.70-71.

[5] J. W. Sun, The Research of Educational Games Design Based on the Flipped Classroom, D, Yunan University. 